\title{
ERRATA
}

\section{ERRATUM: Squeezed states and quantum chaos [JETP 86, 61-70 (January 1998)]}

K. N. Alekseev and D. S. Primak

L. V. Kirenskiu Institute of Physics, Siberian Branch of the Russian, Academy of Sciences, 660036

Krasnoyarsk, Russia

Zh. Éksp. Teor. Fiz. 116, 1499 (October 1999)

[S1063-7761(99)02710-9]

In Ref. 29 and in Conclusions, "Rui-Hua Xie"' should appear instead of "Rui-Pue Xie." We thank Xie for calling our attention to this misprint.

Translated by M. E. Alferieff

\section{ERRATUM: Spectral investigations of surface ordering in ultrathin molecular films [JETP 88, 1005-1009 (May 1999)]}

\author{
V. K. Dolganov, V. M. Zhilin, and K. P. Meletov \\ Institute of Solid-State Physics, Russian Academy of Sciences, 142432 Chernogolovka, Moscow Region, \\ Russia \\ Zh. Éksp. Teor. Fiz. 116, 1499 (October 1999)
}

[S1063-7761(99)02810-3]

In Fig. 6 the ordinate should be designated as $E_{d} \cdot 10^{3}$.

In Fig. 7 the scale divisions along the ordinate should range from 2400 to 3200.

Translated by M. E. Alferieff 